\title{
Recurrent Malignant Thymoma
}

National Cancer Institute

\section{Source}

National Cancer Institute. Recurrent Malignant Thymoma. NCI Thesaurus. Code C7905.

Reemergence of malignant thymoma after a period of remission. 